\title{
Menstrual function among women exposed to polybrominated biphenyls: A follow-up prevalence study
} Stephanie I Davis ${ }^{1}$, Heidi Michels Blanck², Vicki S Hertzberg', Paige E Tolbert ${ }^{1,4}$, Carol Rubin ${ }^{5}$, Lorraine L Cameron ${ }^{6}$, Alden K Henderson ${ }^{5}$ and Michele Marcus*1,4

\author{
Address: ${ }^{1}$ Department of Epidemiology, Rollins School of Public Health, Emory University, 1518 Clifton Road, Alanta, GA, 30322, USA, ${ }^{2}$ Graduate \\ Division of Biological and Biomedical Sciences, Emory University, 1462 Clifton Road, NE, Atlanta, Georgia, 30322, USA, ${ }^{3}$ Department of \\ Biostatistics, Rollins School of Public Health, Emory University, 1518 Clifton Road, NE, Atlanta, Georgia, 30322, USA, ${ }^{4}$ Department of \\ Environmental and Occupational Health, Rollins School of Public Health, Emory University, 1518 Clifton Road, NE, Atlanta, Georgia, 30322, \\ USA, ${ }^{5}$ Division of Environmental Hazards and Health Effects, National Center for Environmental Health, Centers for Disease Control and \\ Prevention, 4770 Buford Highway, MS F-46, Atlanta, Georgia, 30341, USA and 'Division of Environmental and Occupational Epidemiology, \\ Michigan Department of Community Health, P.O. Box 30195, Lansing, Michigan, 48909, USA \\ Email: Stephanie I Davis - sidavis@cdc.gov; Heidi Michels Blanck - hblanck@cdc.gov; Vicki S Hertzberg - vhertzb@sph.emory.edu; \\ Paige E Tolbert - ptolber@sph.emory.edu; Carol Rubin - crubin@cdc.gov; Lorraine L Cameron - CameronL@michigan.gov; \\ Alden K Henderson - ahenderson@cdc.gov; Michele Marcus* - mmarcus@sph.emory.edu \\ * Corresponding author
}

Published: 09 August 2005

Environmental Health: A Global Access Science Source 2005, 4:15 doi:10.1186/ 1476-069X-4-15

This article is available from: http://www.ehjournal.net/content/4/I//5

(C) 2005 Davis et al; licensee BioMed Central Ltd.

This is an Open Access article distributed under the terms of the Creative Commons Attribution License (http://creativecommons.org/licenses/by/2.0), which permits unrestricted use, distribution, and reproduction in any medium, provided the original work is properly cited.

\begin{abstract}
Background: Alteration in menstrual cycle function is suggested among rhesus monkeys and humans exposed to polybrominated biphenyls (PBBs) and structurally similar polychlorinated biphenyls (PCBs). The feedback system for menstrual cycle function potentially allows multiple pathways for disruption directly through the hypothalamic-pituitaryovarian axis and indirectly through alternative neuroendocrine axes.
\end{abstract}

Methods: The Michigan Female Health Study was conducted during 1997-1998 among women in a cohort exposed to PBBs in 1973. This study included 337 women with self-reported menstrual cycles of 20-35 days (age range: 24-56 years). Current PBB levels were estimated by exponential decay modeling of serum PBB levels collected from 1976-1987 during enrollment in the Michigan PBB cohort. Linear regression models for menstrual cycle length and the logarithm of bleed length used estimated current PBB exposure or enrollment PBB exposure categorized in tertiles, and for the upper decile. All models were adjusted for serum PCB levels, age, body mass index, history of at least $10 \%$ weight loss in the past year, physical activity, smoking, education, and household income.

Results: Higher levels of physical activity were associated with shorter bleed length, and increasing age was associated with shorter cycle length. Although no overall association was found between PBB exposure and menstrual cycle characteristics, a significant interaction between PBB exposures with past year weight loss was found. Longer bleed length and shorter cycle length were associated with higher PBB exposure among women with past year weight loss.

Conclusion: This study suggests that PBB exposure may impact ovarian function as indicated by menstrual cycle length and bleed length. However, these associations were found among the small number of women with recent weight loss suggesting either a chance finding or that mobilization of PBBs from lipid stores may be important. These results should be replicated with larger numbers of women exposed to similar lipophilic compounds. 


\section{Background}

In 1973, the fire retardant chemical, FireMaster ${ }^{\circledR}$, was mistaken for NutriMaster ${ }^{\circledast}$, a magnesium oxide-based cattle feed supplement, and was inadvertently introduced into cattle feed (Michigan Chemical Corporation, St. Louis, MI). Thousands of farm families and farm product consumers were exposed to this commercial mixture of polybrominated biphenyl (PBB) congeners throughout Michigan. Concern about possible adverse health effects led to the establishment of the Michigan PBB Long-Term Study in 1976 by the Michigan Department of Community Health $(\mathrm{MDCH})$. The incident is described in detail elsewhere [1,2].

From 1997-1998, the Michigan Female Health Study (MFHS) was conducted to assess whether PBB exposure disrupted endocrine function among cohort women. Only one rhesus monkey study was found, suggesting that PBBs may be associated with longer menstrual cycles [3]. Animal studies of structurally similar polychlorinated biphenyls (PCBs) have found that menstrual cycle length was either not different [4-7] or longer [8] with Aroclor $1248[4,8]$ or Aroclor 1254 [5-7] dosing. Bleed length was marginally longer in the higher Aroclor 1254 dose groups [5-7]. Human PCB studies are also inconsistent. Shorter cycle length was associated with indices of PCB-contaminated fish consumption [9]. When summed over measures of selected PCB congeners, cycle length was longer with higher total PCB levels in a large multicenter cohort [10], but not among Southeast Asian immigrants [11]. Cooper et al reported that bleed length was not associated with PCBs [10], but Yucheng women, with cooking oil exposure to PCBs, reported abnormal bleeding more often than controls [12].

Endocrine regulation is a complex process and may be disrupted at many points. The immune and neuroendocrine systems are integrated in a network of the ovarian, thyroid, thymus, and adrenal axes. This network is regulated or disrupted through feedforward and feedback loops of the hypothalamus, the pituitary, and associated endorgans of the neuroendocrine axes [13-15].

Cycle length and bleed length, although nonspecific, are markers for the reproductive status of women undergoing cyclical ovulation and endometrial angiogenesis under hormonal feedback and control [16-20]. This study assessed whether serum PBB levels were associated with these markers of menstrual cycle function among women still menstruating in the year before interview.

\section{Methods \\ The Michigan Female Health Study design and data collection}

The release of PBBs into the Michigan food chain was limited in geographic distribution and in duration due to the environmental remediation of quarantined farms and the food chain. Michigan PBB cohort enrollment data, along with blood samples for exposure biomonitoring that included PBB and PCB, were collected from 1976-1987 by the MDCH.

The study design of the MFHS is a follow-up prevalence study [21]. It is a hybrid study of an exposure cohort followed prospectively to assess the prevalence of current menstrual cycle outcomes. Data were collected for the MFHS during August 1997 through April 1998 by computer-assisted telephone interview. Participants were asked about reproductive history, menstrual cycle characteristics, physical activity, smoking habits, medication, physician-diagnosed medical conditions, and other health and demographic information. The MFHS was approved by the institutional review boards of Emory University, $\mathrm{MDCH}$, and the Centers for Disease Control and Prevention.

\section{Eligibility for menstrual cycle analyses}

A total of 1020 women in the MFHS had serum levels of PBB available from cohort enrollment. This study was restricted to women who were born before the exposure incident, which is estimated to have occurred as early as July 1, 1973 [22]. In this manner, we restricted the analyses to women solely exposed by food ingestion and not in utero.

Women were asked to report their usual non-pregnancy related cycle length during the past year, defined as the number of days from the first day of menstrual bleed to the first day of the next menstrual bleed. The distribution of menstrual cycle length across the reproductive lifespan represents a mixture between normal ovulatory cycles and short or long anovulatory bleeding episodes at both age extremes [23-25]. Long cycles in the right tail are influenced by older women in perimenopausal status [24,25] with more frequent ovulatory failure [23]. Among women aged 25-44 years, Metcalf observed that $93.6 \%$ of all cycles were between 20-35 days in length with a pattern of consistently ovulatory cycles [23]. We lacked laboratory confirmation and referred to the women in this study as having normal, not ovulatory, cycles. We decomposed the distribution of cycle length into an approximately symmetric part centered about 28 days $(n=338)$ and a long right tail $(\mathrm{n}=12)$. We restricted our analysis to women with cycle lengths ranging from 20-35 days ( $n=337)$, excluding a subject with a 14-day cycle length (Figure 1). Other studies define normal cycles from 21-35 days [26], 


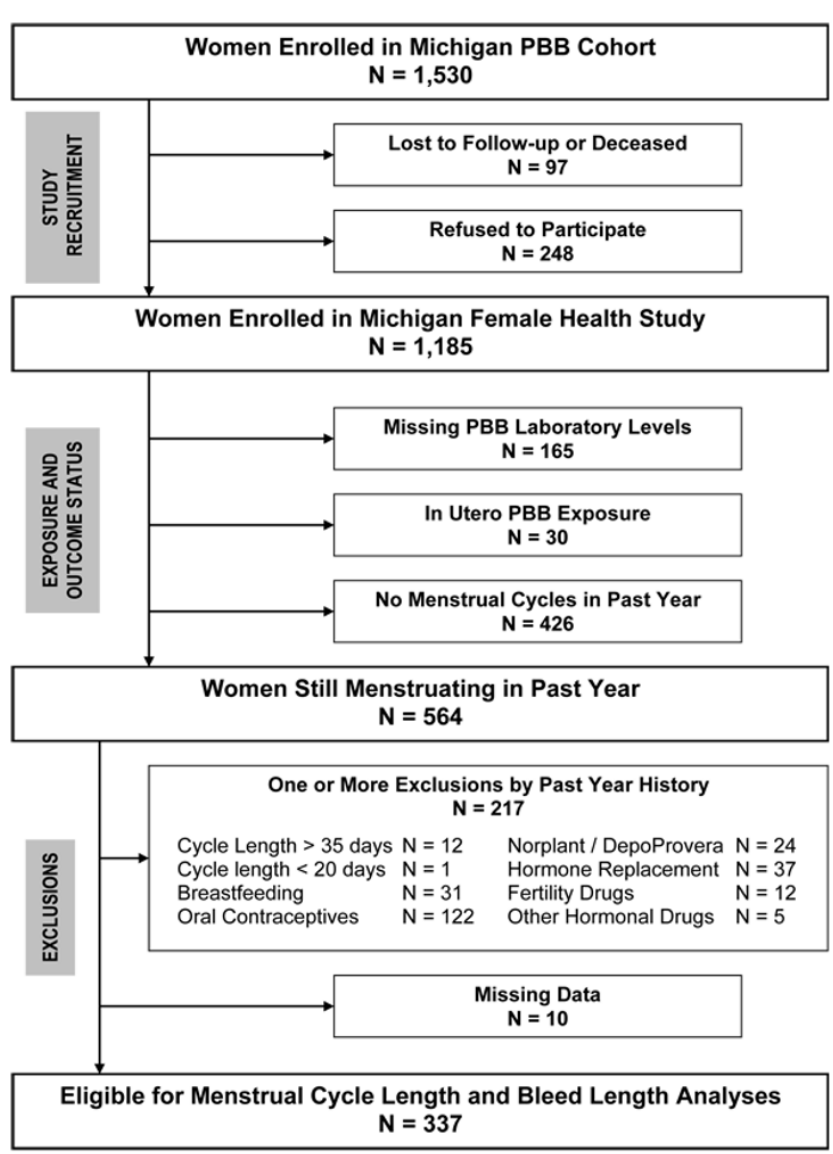

Figure I

Eligibility for menstrual cycle analysis, Michigan Female Health Study, 1997-1998.

in general agreement with our definition, while others recommend cycle lengths of 18-40 days [25].

We excluded women from menstrual cycle analyses if they indicated any of the following during the past year: no menstrual cycles, menstrual cycles shorter than 20 days or longer than 35 days, breastfeeding, or use of hormone medications. We also excluded ten women with missing data (Figure 1).

We restricted bleed length analyses to the same women who were eligible for cycle length analyses. Women reported their usual length of menstrual bleeding in the past year as a single estimate or a range in days. Bleed length for women reporting a range was taken as the midpoint between the two values.

\section{Measurement of enrollment serum PBB and PCB concentrations}

PCBs and PBBs have 209 theoretically possible congeners. By weight, FireMaster ${ }^{\circledast}$ was $54 \%-68 \%$ PBB 153, a noncoplanar congener. Several coplanar congeners were present in the mixture in smaller amounts $[22,27]$. Serum concentrations of PBB 153, in parts per billion (ppb), were quantified by gas chromatography with electron capture detection using established protocols. The limit of detection (LOD) was $1 \mathrm{ppb}$. These PBB 153 measures are indicators of total PBB exposure $[28,29]$.

Up to 1982, total PCBs were quantified as Aroclor 1254 (Montsano Company, St. Louis, MO) levels with the LOD at 5 ppb. Between 1982-1993, Aroclor 1260 (Montsano Company, St. Louis, MO) levels were assessed with the LOD at $3 \mathrm{ppb}$. We combined initial total PCB levels from the two assay methods, assuming any total below $5 \mathrm{ppb}$ was below the LOD. Only three women $(0.9 \%)$ had initial Aroclor 1260 levels, all below 3 ppb. Changing PCB analytical methods did not result in misclassification of exposure rank in this sample.

\section{Estimation of current serum PBB concentration}

We hypothesized that current $\mathrm{PBB}$ levels were associated with current menstrual function. We used serum $\mathrm{PBB}$ enrollment measurements to estimate individual current PBB levels, using an exponential decay model described previously [30]. The original decay model included women who were at least 16 years old at enrollment with initial PBB levels of $2 \mathrm{ppb}$ or higher. They also had at least two nonpregnancy serum samples drawn. The authors found that overall, median half-life was 13.5 years, but decay was slower among women with high enrollment BMI. Parity, age at enrollment, smoking history, and breastfeeding duration were not significant predictors of decay [30]. The estimated levels from the decay model were highly correlated with measured levels $(r=0.92)$ [31].

We used the same equation specified in the decay model for our estimates. We assigned enrollment PBB levels less than or equal to $1 \mathrm{ppb}$ a value of $0.5 \mathrm{ppb}$, a value half way between zero and the LOD. This enabled log-transformations [32], and has been shown to be an appropriate imputation technique [33]. We included data from the MDCH archives: linear and quadratic terms for the logarithm of enrollment PBB level, categories of body mass index (BMI) at enrollment (less than/greater than or equal to $23.0 \mathrm{~kg} / \mathrm{m}^{2}$ ), and age at enrollment. We also included data from the MFHS: number of full-term pregnancies between enrollment and interview, breastfeeding duration (months), and smoking status (ever/never). Because these data were modeled, we did not impose an LOD on the estimated levels. 


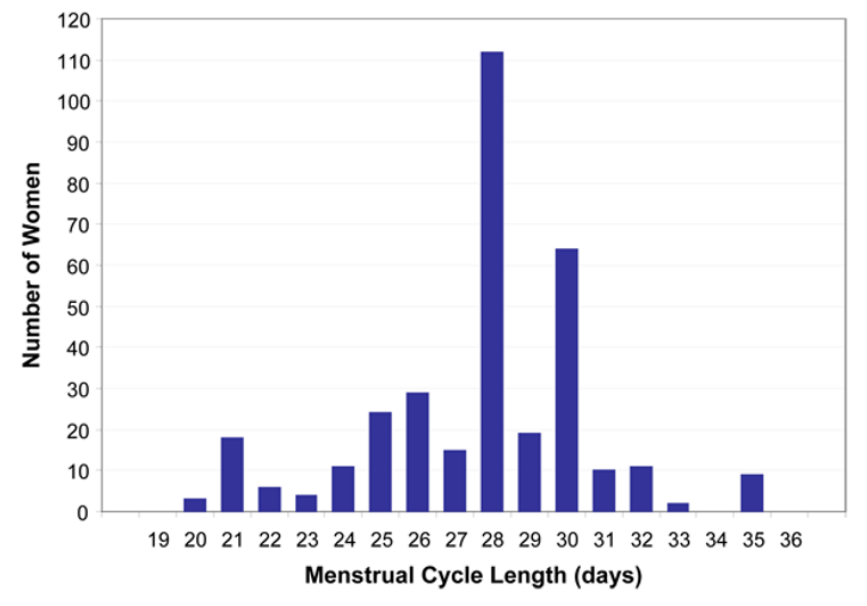

Figure 2

Distribution of menstrual cycle length, Michigan Female Health Study, 1997-1998

\section{Classification of estimated current PBB exposure}

PBB and PCB exposures were ranked in low, middle, and high exposure categories. Tertiles were our primary classification for estimated current PBBs: with low, from zero to $0.06 \mathrm{ppb}(\mathrm{n}=112)$ as referent; middle, from greater than $0.06-0.32 \mathrm{ppb}(\mathrm{n}=113)$; and high, at greater than 0.32 $\mathrm{ppb}(\mathrm{n}=112)$. We also performed analyses with estimated current PBBs categorized for highest exposure, retaining the lowest tertile as the referent and classifying the upper decile at greater than $3.08 \mathrm{ppb}(\mathrm{n}=35)$.

\section{Classification of PBB exposure at cohort enrollment}

We categorized laboratory measures of PBB at enrollment into approximate tertiles: at or below the LOD of $1 \mathrm{ppb}(\mathrm{n}$ $=111)$ as referent; from greater than 1 to $3 \mathrm{ppb}(\mathrm{n}=120)$; and greater than $3 \mathrm{ppb}(\mathrm{n}=106)$. We classified enrollment PBB levels greater than $12 \mathrm{ppb}(\mathrm{n}=37)$ as the upper decile, retaining the same referent group.

\section{Classification of PCB exposure}

We used initial serum PCB measurements. We did not attempt to model the decay and bioaccumulation of PCBs due to changes in the laboratory assessment from Aroclor 1254 to Aroclor 1260. We also did not have information on important factors of PCB bioaccumulation, such as fish consumption. We divided PCB exposure into four categories. The lowest referent category included measurements at or below the LOD or $5 \mathrm{ppb}(\mathrm{n}=178)$; the middle category, from greater than 5 to $7 \mathrm{ppb}(\mathrm{n}=53)$; the high category, at greater than $7 \mathrm{ppb}(\mathrm{n}=62)$; and missing $(\mathrm{n}=$ 44).

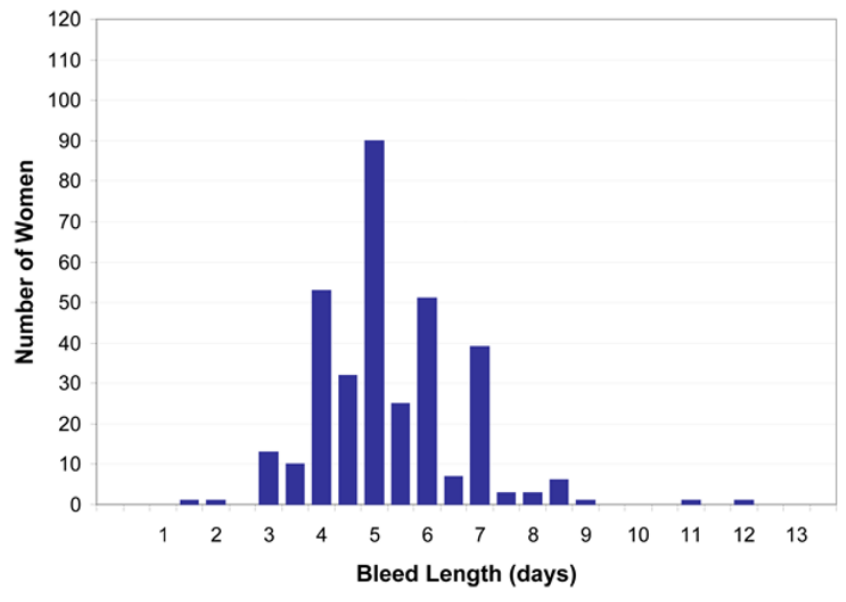

Figure 3

Distribution of bleed length, Michigan Female Health Study, 1997-1998

\section{Statistical analyses}

We performed multiple linear regressions with cycle length and with the natural logarithm of bleed length as continuous outcomes. We examined the distributions of the continuous variables to better meet the assumptions of normality in linear regression models. We did not apply data transformations for age and BMI at interview, or for cycle length restricted to 20-35 days (median 28.0; mean 27.7 days; standard deviation (SD) 2.9; skewness 0.42 ; kurtosis 0.70) (Figure 2). Bleed length was rightskewed (median 5.0; mean 5.3; SD 1.3; skewness 0.87; kurtosis 2.5) (Figure 3). We log-transformed bleed length to center the distribution (median 1.61; mean 1.63; SD 0.25; skewness -0.37; kurtosis 1.91). We verified that the quantile-quantile (QQ) plot for log-transformed bleed length linearized the curved point pattern we observed in the QQ plot for bleed length. We performed collinearity diagnostics, and centered age and BMI about their respective means $\left(37.8\right.$ years and $26.6 \mathrm{~kg} / \mathrm{m}^{2}$ ) to reduce inflated variances in the models.

We retained the same covariates in all regression models across both cycle length and bleed length analyses. Categorical covariates included PCBs, usual weekly physical activity, smoking status, educational attainment, income level, and loss of $10 \%$ of body weight or more in the past year unrelated to pregnancy. We defined never exercising as low, one or two times per week as moderate, and exercising three or more times per week as high levels of recreational physical activity. 
Table I: Characteristics of 337 women,* Michigan Female Health Study, 1997-1998.

\begin{tabular}{|c|c|c|}
\hline \multicolumn{2}{|l|}{ Population Characteristics } & Distribution \\
\hline \multicolumn{2}{|l|}{ Continuous Variables } & Point Estimate (Range) \\
\hline \multicolumn{2}{|c|}{ Median PBB level (ppb) measured at cohort enrollment } & $2.0(0.5-1490)$ \\
\hline \multicolumn{2}{|c|}{ Median PBB level (ppb) estimated at study interview } & $0.1(0-1005)$ \\
\hline \multicolumn{2}{|c|}{ Median initial PCB level ( $\mathrm{ppb}$ ) measured in cohort follow-up } & $5.0(1.5-78) \dagger$ \\
\hline \multicolumn{2}{|l|}{ Mean age (years) at study interview } & $37.8(24-56)$ \\
\hline \multicolumn{2}{|l|}{ Mean BMI $\left(\mathrm{kg} / \mathrm{m}^{2}\right)$ at study interview } & $26.6(16.9-53.1)$ \\
\hline \multicolumn{2}{|l|}{ Categorical Variables } & $N(\%)$ \\
\hline \multirow[t]{2}{*}{ Past Year History of Weight Loss $=10 \%$} & No & $293(86.9 \%)$ \\
\hline & Yes & $44(13.0 \%)$ \\
\hline \multirow[t]{3}{*}{ Amount of weekly exercise } & Low (Never) & $48(14.2 \%)$ \\
\hline & Moderate (I or 2 times) & $137(40.6 \%)$ \\
\hline & High ( 3 or more times) & $152(45.1 \%)$ \\
\hline \multirow[t]{2}{*}{ Lifetime smoking status } & Never Smoker & $222(65.9 \%)$ \\
\hline & Ever Smoker & $115(34.1 \%)$ \\
\hline \multirow[t]{3}{*}{ Educational attainment } & High School Grad or Less & $132(39.2 \%)$ \\
\hline & Some College or Technical & $110(32.6 \%)$ \\
\hline & College or Postgrad & $95(28.2 \%)$ \\
\hline \multirow[t]{3}{*}{ Annual Household Income } & Less Than $\$ 35,000$ & $113(33.5 \%)$ \\
\hline & At Least $\$ 35,000$ & $207(61.4 \%)$ \\
\hline & Unknown & $17(5.0 \%)$ \\
\hline
\end{tabular}

* Cycle lengths ranging from 20-35 days. †44 missing PCB levels.

We evaluated interactions of PBB categories with age and BMI at interview, weight loss, and physical activity for all models. Interaction assessment for age or BMI with PBBs included testing linear and quadratic terms. When significant interactions between age and PBB categories were detected, diagnostic tests were repeated with age quintiles. The age range for the first quintile was $24-31$ years $(\mathrm{n}=$ 59); the second, $32-35$ years $(\mathrm{n}=70)$; the third, $36-38$ years $(n=64)$ as the referent group; the fourth, 39-43 years $(n=74)$; and the fifth, $44-56$ years $(n=70)$. We also evaluated possible additive or synergistic effects between exposures to PBBs and PCBs or cigarette smoking by interaction assessment. We exponentiated point estimates and confidence intervals for the difference in the logarithm of bleed length and reported the converted differences in bleed length as a ratio on the original scale, in days.

The decay model we used to estimate current PBB levels was originally developed using different criteria than the inclusion criteria for this study. We performed sensitivity analyses by repeating our models excluding females less than 16 years at enrollment $(n=140)$.

We performed secondary analyses for the full distribution of menstrual cycle length, including women in the long right tail. Logistic regression models would not converge due to small cell sizes with long cycles classified as greater than 35 days $(\mathrm{n}=12 ;$ upper $3 \%)$. We redefined long cycles as greater than 30 days ( $n=43$; upper $10 \%)$ and examined the relationship between current estimated PBB exposure and the prevalence of long cycles.

We retained women with self-reported thyroid conditions $(\mathrm{n}=39,11.6 \%)$ in analyses to avoid adjusting for possible PBB-related thyroid-mediated menstrual cycle effects [3441]. We did not include in utero diethylstilbestrol exposure as a covariate or exclusion due to the high number of women reporting unknown exposure status $(\mathrm{n}=101$, $30.0 \%)$. Five women $(1.5 \%)$ reported having in utero diethylstilbestrol exposure. We performed sensitivity analysis removing these five women from the final models. Most women lacked historical pesticide information ( $\mathrm{n}=298 ; 88.4$ percent $)$; therefore, it was not included in this analysis.

We performed Pearson partial correlation analyses between cycle length and the logarithm of bleed length, assessing overall associations and correlations stratified by history of weight loss. We also performed correlation analyses between the logarithm of both PBB and PCB, and age in years. All analyses were performed using SAS Version 9.1 (SAS Institute Inc., Cary, NC). 
Table 2: Cross tabulation of PBB tertiles from two timeframes, Michigan Female Health Study, 1997-1998.

\begin{tabular}{|c|c|c|c|c|}
\hline \multirow{2}{*}{$\begin{array}{l}\text { No. in Tertiles of PBB } \\
\text { Exposure Measured at } \\
\text { Cohort Enrollment, } \\
\text { (Range, Ppb) }\end{array}$} & \multicolumn{3}{|c|}{ No. in Tertiles of PBB Exposure Estimated at Time of Study Interview (Range, ppb) } & \multirow[t]{2}{*}{ Total No. } \\
\hline & Low $(0.00-0.06)$ & Middle $(>0.06-0.32)$ & High $(>0.32)$ & \\
\hline Low $(\leq 1.0)$ & 84 & 27 & 0 & 111 \\
\hline Middle (I.0-3.0) & 23 & 69 & 28 & 120 \\
\hline High $(>3.0)$ & 5 & 17 & 84 & 106 \\
\hline Total No. & 112 & 113 & 112 & 337 \\
\hline
\end{tabular}

Table 3: Menstrual cycle outcomes by PBB tertiles from two time frames, Michigan Female Health Study, $1997-1998$.

\begin{tabular}{|c|c|c|c|c|c|c|c|c|}
\hline \multirow[t]{2}{*}{ Outcomes } & \multicolumn{3}{|c|}{$\begin{array}{l}\text { Tertiles of PBB Estimated at Study Interview } \\
\text { (No.) }\end{array}$} & \multirow[t]{2}{*}{$P *(d f)$} & \multicolumn{3}{|c|}{$\begin{array}{c}\text { Tertiles of PBB Measured at Cohort } \\
\text { Enrollment (No.) }\end{array}$} & \multirow[t]{2}{*}{$P *(d f)$} \\
\hline & Low (II2) & Middle(II3) & High (II2) & & Low (III) & Middle (I20) & High (106) & \\
\hline $\begin{array}{l}\text { Mean Cycle } \\
\text { Length (SD), } \\
\text { days }\end{array}$ & $27.4(3.1)$ & $28.0(2.9)$ & $27.7(2.8)$ & $0.33(2)$ & $27.5(3.0)$ & $27.6(2.8)$ & $28.0(3.0)$ & $0.34(2)$ \\
\hline $\begin{array}{l}\text { Mean Bleed } \\
\text { Length (SD), } \\
\text { days }{ }^{\dagger}\end{array}$ & $5.0(1.3)$ & $5.1(1.3)$ & $5.2(1.3)$ & $0.36(2)$ & $4.9(1.3)$ & $5.1(1.3)$ & $5.3(1.3)$ & $0.14(2)$ \\
\hline
\end{tabular}

* ANOVA $\mathrm{F}$ test for continuous variables. † Exponentiated from log(bleed length).

\section{Results}

Descriptive statistics of the study population

After restricting our sample to women with cycle lengths between 20-35 days, average cycle and bleed lengths were 27.7 days and 5.3 days, respectively. The women, all white, ranged in age from 24 to 56 years. Most never smoked and reported some form of weekly exercise. Educational attainment was evenly distributed across PBB tertiles. Forty-four women (13.0\%) reported losing $10 \%$ or more of their body weight in the past year (Table 1).

In our sample, 318 women (94.4\%) had enrolled in the cohort by the end of 1977 . The remaining 19 (5.6\%) enrolled over the next 9 years. Using the exponential decay model [30], we extrapolated enrollment levels of PBB over an average of 20.5 years (median: $20.6 ; 25^{\text {th }} \%$ : $20.3 ; 75^{\text {th }} \%$ : 20.9 ; range: $10.3-22.4$; in years) to estimate PBB levels at the time of the MFHS interview. Most women categorized as having low, middle, or high PBB exposure at enrollment were classified the same way by estimated current PBB tertiles (75.7\%, 57.5\%, and 79.2\%, respectively in Table 2). If laboratory LODs were applied to the decay estimates, 277 women $(82.2 \%)$ would cur- rently have PBB levels below $1 \mathrm{ppb}$ (median: 0.13 ; mean: $7.73 ; 25^{\text {th }} \%$ : $0.03 ; 75^{\text {th }} \%$ : 0.51 ; range: $0-1005 ;$ in $\left.\mathrm{ppb}\right) . A$ total of 86 women were common to our study $(25.5 \%$ of $337)$ and the decay study (22.6\% of 380$)$.

We observed digit preferences in reporting menstrual cycle length for 30 days and 7-day multiples, noting peaks at $21(\mathrm{n}=18), 28(\mathrm{n}=112)$, and $30(\mathrm{n}=64)$ days (Figure 2 ). The distribution of bleed length did not exhibit digit preferences. Because we allowed women to report their usual bleed length either directly or in a range, 84 women $(24.9 \%)$ had half-day estimates (Figure 3 ).

\section{Crude associations between PBB, PCB, and population characteristics}

Average cycle length did not differ among women when stratified by PBB exposure at enrollment or by PBB exposure estimated at the time of the interview. There was a suggested increase in bleed length with increasing PBB tertiles at enrollment and time of interview (Table 3 ).

Age and BMI were positively correlated $(\mathrm{r}=0.13, \mathrm{p}=$ 0.02 ). The data suggested that women in the lowest tertile 
Table 4: Menstrual cycle covariates by PBB tertiles from two time frames, Michigan Female Health Study, $1997-1998$.

\begin{tabular}{|c|c|c|c|c|c|c|c|c|}
\hline \multirow[t]{2}{*}{ Covariates } & \multicolumn{3}{|c|}{$\begin{array}{l}\text { Tertiles of PBB Estimated at Study Interview } \\
\text { (No.) }\end{array}$} & \multirow[t]{2}{*}{$P *(d f)$} & \multicolumn{3}{|c|}{$\begin{array}{c}\text { Tertiles of PBB Measured at Cohort } \\
\text { Enrollment (No.) }\end{array}$} & \multirow[t]{2}{*}{$P *(d f)$} \\
\hline & Low (112) & Middle (I I3) & High (II2) & & Low (III) & Middle (120) & High (106) & \\
\hline \multicolumn{9}{|l|}{ Continuous Variables } \\
\hline Mean Age (SD), years & $37.7(6.9)$ & $36.8(6.1)$ & $38.8(6.9)$ & $0.07(2)$ & $38.9(6.4)$ & $37.1(6.4)$ & $37.3(7.2)$ & $0.07(2)$ \\
\hline Mean BMI (SD), kg/m² & $25.8(5.4)$ & $26.9(6.5)$ & $27.0(6.8)$ & $0.28(2)$ & $27.5(6.4)$ & $26.3(6.4)$ & $25.8(5.9)$ & $0.12(2)$ \\
\hline \multicolumn{9}{|c|}{ Amount of Weekly Exercise } \\
\hline Low No. (\%) & $14(12.5)$ & $17(15.0)$ & $17(15.2)$ & $0.27(4)$ & $13(\mid 1.7)$ & $15(12.5)$ & $20(18.9)$ & $0.27(4)$ \\
\hline Moderate No. (\%) & $38(33.9)$ & $48(42.5)$ & $51(45.5)$ & & $41(36.9)$ & $50(4 \mid .7)$ & $46(43.4)$ & \\
\hline High No. (\%) & $60(53.6)$ & $48(42.5)$ & $44(39.3)$ & & $57(51.4)$ & $55(45.8)$ & 40 (37.7) & \\
\hline \multicolumn{9}{|c|}{ Past Year History of Weight Loss $=10 \%$} \\
\hline Without No. (\%) & $95(84.8)$ & $97(85.8)$ & $101(90.2)$ & $0.45(2)$ & $97(87.4)$ & $103(85.8)$ & $93(87.7)$ & $0.90(2)$ \\
\hline With No. (\%) & $17(15.2)$ & $16(14.2)$ & II (9.8) & & $14(12.6)$ & $17(14.2)$ & $13(12.3)$ & \\
\hline
\end{tabular}

* ANOVA F test for continuous variables; Chi square test for categorical variables.

of enrollment PBBs were older and had higher BMIs; conversely, women in the highest tertile of estimated current PBBs were older and had higher BMIs (Table 4). Previously, Blanck et al also noted slower PBB decay among women with higher BMIs [30]. We found little difference in the frequency of weight loss in the past year and in the usual levels of weekly physical activity by PBB tertiles (Table 4).

The frequency of diagnosed thyroid conditions did not differ across either PBB tertiles estimated at interview or measured at enrollment ( $\mathrm{p}=0.76$ and 0.46 , respectively; 2 df). Mean menstrual cycle length and bleed length did not differ when stratified by history of thyroid disorders ( $p=0.09$ and 0.58 , respectively; $1 \mathrm{df}$ ). Enrollment PBBs and enrollment PCBs were positively correlated among the 293 women with both measures available $(\mathrm{r}=0.12, \mathrm{p}$ = 0.04); however, estimated current PBBs and enrollment PCBs, were not $(\mathrm{r}=0.06, \mathrm{p}=0.27)$. Age was positively correlated with PCBs $(\mathrm{r}=0.18, \mathrm{p}=0.002)$, but not PBBs (enrollment: $r=-0.09, p=0.10$; adjusted current: $r=0.02$, $\mathrm{p}=0.66)$.

\section{Multiple regression models for cycle length and bleed length}

No grossly influential observations were noted in model diagnostics. The adjusted $\mathrm{R}^{2}$ values for linear regression models were $5 \%$ for cycle length and $7 \%$ for the logarithm of bleed length.

We observed an association between physical activity and bleed length, but not cycle length, regardless of PBB categories used in the models. Women with high levels of physical activity had bleed lengths 0.92 times shorter than those with moderate levels (95\% confidence limits: 0.87 , $0.97)$.

We found no overall association between current estimated PBBs and either menstrual cycle length or bleed length; however, the associations between PBB exposure and menstrual cycle length or bleed length differed for women based on their history of weight loss in the past year. The interaction terms for past year weight loss and PBB tertiles were not statistically significant for cycle length (Table 5). When we considered women with weight loss in the highest decile of estimated current PBB exposure, the interaction term was significant. This small group of women $(n=4)$ had cycle lengths 3.55 days shorter (95\% confidence limits: $-6.45,-0.65)$ than the referent group. We observed a similar association using upper decile enrollment PBB levels with even fewer women with weight loss $(\mathrm{n}=3)$. Their mean cycle lengths were 5.54 days shorter (95\% confidence limits: -8.83, 2.26) than their respective referent group. These three were among the four women with weight loss in the upper decile of estimated current PBBs.

Women with weight loss also exhibited a monotonic increase in bleed length with increasing PBB exposure relative to referent women in the low PBB tertile without weight loss. Among women with weight loss in estimated current PBB tertiles, those in the low tertile had shorter bleed lengths than the referent group with a ratio of 0.82 ; those in the middle tertile had a bleed length ratio of 0.92 ; and those in the high tertile had longer bleed lengths with a ratio of 1.27 (test for interaction: $\mathrm{p}<0.0001$ ) (Table 6). 
Table 5: Cycle length by weight loss and PBB tertiles, Michigan Female Health Study, 1997-1998. Adjusted for PCB, BMI and age at interview, physical activity, smoking history, education, income.

\begin{tabular}{|c|c|c|c|c|c|c|}
\hline & \multicolumn{6}{|c|}{ Difference in Cycle Length, (days) } \\
\hline & \multicolumn{3}{|c|}{ Without Weight Loss } & \multicolumn{3}{|c|}{ With Weight Loss } \\
\hline & No. & Diff & $(95 \% \mathrm{Cl})$ & No. & Diff & $(95 \% \mathrm{Cl})$ \\
\hline \multicolumn{7}{|c|}{ Tertiles of PBB Estimated at Study Interview $\S$} \\
\hline Low & 95 & 0.00 & Ref & 17 & -0.28 & $(-1.79$ to 1.22$)$ \\
\hline Middle & 97 & 0.35 & $(-0.48$ to 1.18$)$ & 16 & 0.21 & $(-1.34$ to 1.76$)$ \\
\hline High & 101 & 0.30 & $(-0.53$ to 1.13$)$ & 11 & -1.04 & $(-2.86$ to 0.77$)$ \\
\hline \multicolumn{7}{|c|}{ Test for Interaction: $\mathrm{p}=0.57,2 \mathrm{df}$} \\
\hline \multicolumn{7}{|c|}{$\begin{array}{l}\text { Tertiles of PBB } \\
\text { Measured at } \\
\text { Cohort } \\
\text { Enrollment }\end{array}$} \\
\hline Low & 97 & 0.00 & Ref & 14 & 0.35 & $(-1.27$ to 1.98$)$ \\
\hline Middle & 103 & 0.01 & $(-0.80$ to 0.82$)$ & 17 & -1.02 & $(-2.53$ to 0.48$)$ \\
\hline High & 93 & 0.54 & $(-0.30$ to 1.39$)$ & 13 & -0.22 & $(-1.88$ to 1.46$)$ \\
\hline \multicolumn{7}{|c|}{ Test for Interaction: $p=0.45,2 \mathrm{df}$} \\
\hline
\end{tabular}

* Cycle lengths ranging from $20-35$ days.

Table 6: Bleed length by weight loss and PBB tertiles, Michigan Female Health Study, 1997-1998. Adjusted for PCB, BMI and age at interview, physical activity, smoking history, education, income.

\begin{tabular}{|c|c|c|c|c|c|c|}
\hline & \multicolumn{6}{|c|}{ Ratio of Bleed Length * } \\
\hline & \multicolumn{3}{|c|}{ Without Weight Loss } & \multicolumn{3}{|c|}{ With Weight Loss } \\
\hline & No. & Ratio & $(95 \% \mathrm{Cl})$ & No. & Ratio & $(95 \% \mathrm{Cl})$ \\
\hline \multicolumn{7}{|c|}{ Tertiles of PBB Estimated at Study Interview $\S$} \\
\hline Low & 95 & 1.00 & Ref & 17 & 0.82 & $(0.72$ to 0.93$)$ \\
\hline Middle & 97 & 0.92 & $(0.85$ to $\mathrm{I} .0 \mathrm{I})$ & 16 & 0.92 & $(0.80$ to 1.06$)$ \\
\hline High & 101 & 1.00 & (0.91 to 1.09$)$ & II & 1.27 & ( 1.08 to 1.50$)$ \\
\hline \multicolumn{7}{|c|}{ Test for Interaction: $\mathrm{p}<0.000 \mathrm{I}, 2 \mathrm{df}$} \\
\hline \multicolumn{7}{|c|}{ Tertiles of PBB Measured at Cohort Enrollment } \\
\hline Low & 97 & 1.00 & Ref & 14 & 0.89 & $(0.78$ to 1.03$)$ \\
\hline Middle & 103 & 1.03 & $(0.96$ to 1.10$)$ & 17 & 0.98 & (0.86 to 1.12$)$ \\
\hline High & 93 & 1.03 & $(0.96$ to 1.11$)$ & 13 & 1.16 & (1.00 to 1.34$)$ \\
\hline \multicolumn{7}{|c|}{ Test for Interaction: $p=0.08,2 \mathrm{df}$} \\
\hline
\end{tabular}

* Exponentiated from difference in log(bleed length).

We observed consistent results in the model examining the upper decile (test for interaction: $\mathrm{p}=0.002$, data not shown). We also noted PBB-weight loss interactions with enrollment PBB tertiles that were consistent with the models for estimated current PBB tertiles and bleed length (test for interaction: $\mathrm{p}=0.08$ ) (Table 6 ).
We also examined the cumulative distribution functions (CDF) for log-transformed current estimated PBBs. There was no difference in the distribution of PBBs between women who did and did not report past year weight loss (exact two-sided Wilcoxon $\mathrm{p}=0.61$ ). We further examined the CDFs for PBB distributions among the 44 women with past year weight loss by menstrual cycle length and bleed length categories (Figure 4). We dichotomized PBB 
strata for shorter cycle length in the lower quartile $(\leq 25$ days) and also for longer bleed length in the upper quartile ( $\geq 6$ days). CDFs for PBBs did not differ for women with shorter cycle lengths (Wilcoxon $\mathrm{p}=0.63$ ); however, the CDFs for PBBs stratified for longer bleed length were different (Wilcoxon $\mathrm{p}=0.006$ ). We observed that women who had longer bleed lengths with past year weight loss were more likely to have higher PBB levels (Figure 4).

Aging one year shortened cycle length by 0.10 day ( 95 percent confidence interval: -0.14 to -0.05 ) regardless of the PBB categories included in multiple regression models. Bleed length had a J-shaped relationship with age that was modified by estimated current PBB categories (tertile and decile models, tests for interaction: $\mathrm{p}=0.04$ ). Due to the curvilinear effect with age modeled as a continuous variable, a clear dose-response in these models was difficult to discern. Therefore, we repeated tests for these interactions with age quintiles cross-classified with estimated current PBB categories (tertile model: $\mathrm{p}=0.03$; decile model: $\mathrm{p}=$ 0.01 ). The women who were $24-31$ years old in the upper tertile of estimated PBB exposure $(n=17)$ had bleed lengths 0.79 times shorter than the 36 to 38 year olds in the lowest tertile $(\mathrm{n}=20)$ (95 percent confidence interval: $0.67,0.93)$. The $24-31$ year olds in the upper decile of exposure $(\mathrm{n}=8)$ had bleed lengths 0.70 times shorter $(95$ percent confidence interval: 0.57, 0.87). We did not observe the same effect for bleed length with enrollment level PBBs. The MFHS women in the youngest age quintile $(n=59)$ were $6-13$ years old at the time of the Michigan incident.

In our sensitivity analysis of women who were the same age as those in the exponential decay model, we excluded 140 women less than 16 years at enrollment $(41.5 \%)$. We found that, despite this restriction to 197 women, all significant PBB-weight loss interactions persisted for both cycle length (adjusted PBB for upper decile, $\mathrm{p}=0.04$; initial PBB for upper decile, $\mathrm{p}=0.02$ ) and bleed length (adjusted PBB tertiles and upper decile, $\mathrm{p}<0.0001$; initial PBB tertile, $\mathrm{p}=0.01$; initial PBB for upper decile, 0.04). For the PBB-age interaction for bleed length with estimated current PBBs, we no longer noted a significant age interaction (tertile model: $\mathrm{p}=0.38$; decile model: $\mathrm{p}=$ 0.32 ). This is reasonable due to the age restriction imposed on this even smaller sample of women. In addition, among the 197 women, age was no longer an independent predictor of cycle length.

We tested the interaction between PBBs and PCBs for the full sample of 337 women including 44 women missing PCBs, and for the subset of 293 women with both PBB and PCB measures available. No significant interactions were detected for either enrollment or estimated current PBBs with enrollment PCBs, for either cycle length or

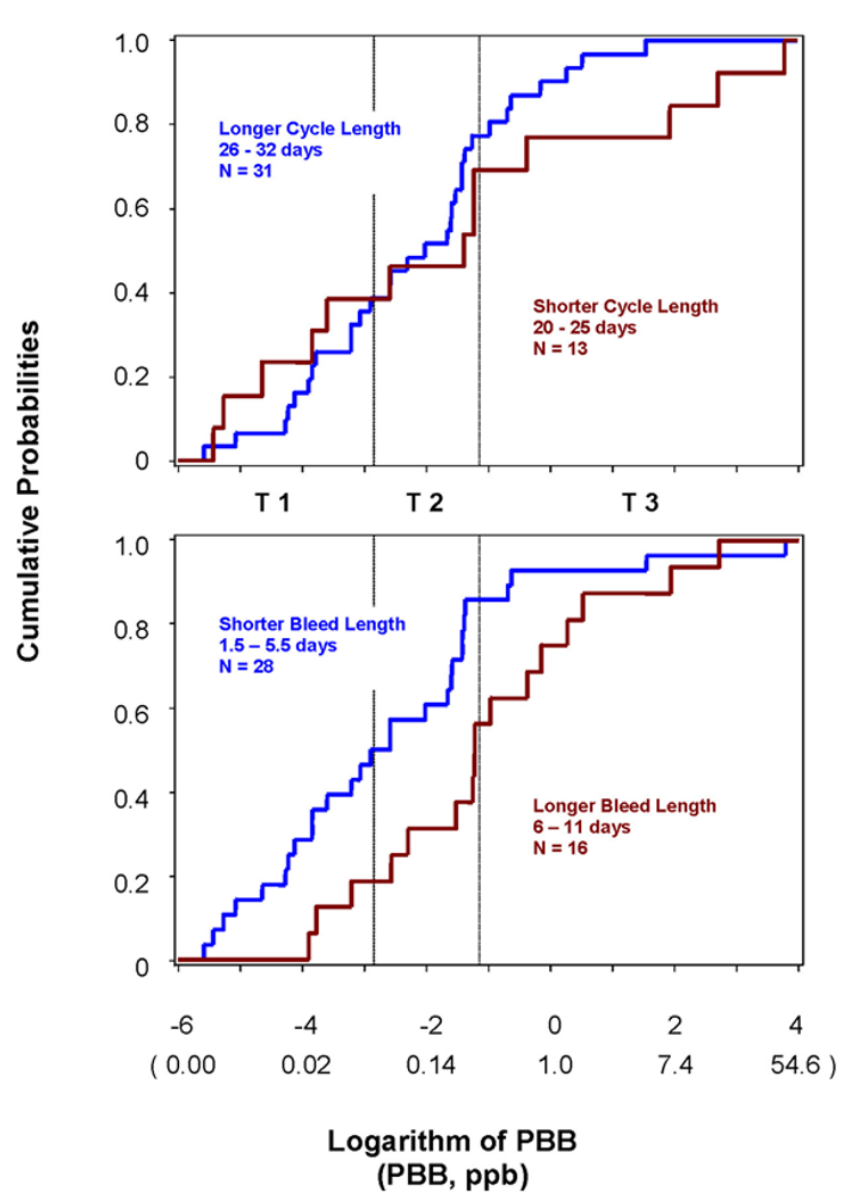

\section{Figure 4}

Cumulative distribution functions for estimated current $\log$ (PBB) among women with weight loss.

Shorter cycle length defined as lower 25 th\%. Longer bleed length defined as upper $75^{\text {th }} \%$. TI = Low Tertile; T2 = Middle Tertile; $\mathrm{T3}=$ High Tertile.

bleed length. In our secondary analysis of long cycle length, we found no overall association between PBB exposure and menstrual cycle length greater than 30 days $(\mathrm{n}=43$; upper $10 \%)$.

In addition, the sensitivity analyses removing the five women with in utero DES exposure did not affect our results.

\section{Discussion}

Normal menstrual cyclicity is a marker of successful follicular recruitment and ovulation. Factors such as aging, weight loss, body composition, and physical activity are thought to affect menstrual cycle function through the hypothalamic-pituitary-adrenal axis [42-52]. Physical 
activity and age were associated with menstrual cycle function in this sample of women. We observed bleed length shortening with increased physical activity that was consistent with the literature $[45,46]$. We did not observe menstrual cycle lengthening with physical activity as was reported in another sample of Michigan women [47]. Our observation of cycle length shortening with increasing age is supported by the literature as well. Older women who are still menstruating exhibit accelerated development of dominant follicles and shorter mean cycle lengths due to shorter follicular phases [53], and follicle density has been clinically measured and mathematically modeled to decrease with age [54-56].

Weight loss, lactation, and pregnancy mobilize lipophilic chemicals like PBBs, normally resistant to elimination, from adipose tissue into systemic circulation, and potentially induce menstrual cycle and other endocrine changes [57-61]. We found no overall association between PBB exposure and menstrual cycle length or bleed length, but significant interactions between $\mathrm{PBB}$ exposure and past year weight loss not related to pregnancy were found for both cycle length and bleed length. Our results were consistent for both estimated current and measured enrollment PBB concentrations. Among women with weight loss, those in the highest tertile of $\mathrm{PBB}$ exposure experienced longer bleed length than women in the lowest tertile. Among the women in the lowest PBB tertile with weight loss, we observed shorter bleed length, as might be expected among women with weight loss in the general population [48-51]. We did not observe any differences in cycle length with PBB exposure or weight loss when PBB was categorized in tertiles. However, among the small number of women in the upper decile of PBB exposure who experienced weight loss, cycle length was shorter by 3.5 days. The direction of this effect is consistent with observations of women exposed to PCBs through fish consumption [9], but not with the longer cycles observed by Cooper et al in their multicenter cohort [10]. On the other hand, we observed no association between PCB exposure and menstrual cycle length or bleed length. Multiple testing and small numbers were a major concern. It is possible that our results were due to chance or artifactual findings. We did, however, observe the same cycle length and bleed length differences among women with weight loss when we restricted our analysis to an even smaller subsample of 197 women at least 16 years old at cohort enrollment.

We also observed significant age-related interactions with PBB exposure for bleed length. We found no evidence in the literature that bleed length is a correlate of age among regularly cycling women in the general population. We observed age-related bleed length differences only in association with current estimated PBB exposure, not with measured enrollment PBB levels. The observed age interaction with $\mathrm{PBB}$ exposure could have been spuriously introduced by the exponential decay model we used to estimate current PBB exposure or from small numbers. Nevertheless, we found that women who were 6-13 years old at the time of the Michigan incident (now 24-31 years) in the highest tertile and decile of current estimated PBBs had shorter bleed length relative to 36-38 year old women in the low tertile $(n=20)$. We restricted women in this study to those who were not transplacentally exposed to PBBs. Therefore, our sample was restricted to women who were exposed to PBBs only by the oral route. The age interaction we observed may indicate that women who were orally exposed before they reached menarche may have been affected during developmental maturation toward menses. Eskenazi et al reported longer cycle length in relation to higher levels of postnatal premenarcheal dioxin exposure, but no differences in bleed length [62]. Blanck et al found earlier age at menarche among a different sample of Michigan girls exposed both in utero to high maternal PBB levels and through breastfeeding [31]. These studies suggest that reproductive events may be affected by the timing and route of developmental and pre-pubertal exposure to halogenated hydrocarbons.

Laboratory assays of urine hormone levels have been useful to document concomitant ovulatory status with selfreported cycle length and bleed length $[11,22]$. Our reliance on self-reported menstrual cycle information alone is a limitation reported by others $[10,63]$ and may be a source of misclassification. The resulting bias from selective over-reporting of certain days would most likely weight the resulting differences in cycle length toward the median (or toward the null hypothesis) (Figure 2). We did not observe digit preferences in the distribution of bleed length (Figure 3). Bleed length, normally shorter in duration compared to cycle length, may be less prone to recall bias. A larger sample and prospectively collected menstrual data would improve the reliability of these selfreported outcome measures.

We were also limited by our reliance on decay estimates of current PBB exposure. Uncertainties in the original decay model were previously described: lack of information on weight gain or loss during cohort follow-up; lack of fasting requirements for blood draws; lack of serum lipid standardization of the PBB measures; detection methods evolving over time; and most women having only two PBB measurements [30]. Strengths of the decay model over previous PBB half-life studies included: inclusion of PBB determinations over longer follow-up; inclusion of women at much lower initial PBB levels; inclusion of a much larger sample of women; and in addition to age and $\mathrm{BMI}$, the inclusion of information on breastfeeding duration, smoking, and parity [30]. 
Eligibility requirements for our study differed from the decay model study. The decay analysis restricted inclusion to females who were at least 16 years of age. Our lower age bound only required women to have been born before the contamination episode. Our sensitivity analysis excluding females below 16 years found similar results to our full model. We also included women with enrollment PBB levels below $2 \mathrm{ppb}(\mathrm{n}=112)$, essentially those women in our low enrollment tertile below the LOD (Table 2). It is possible that different kinetics apply at levels below the lower enrollment PBB inclusion bound of the decay model. The decay model found that half-life was shorter among women with low compared to high enrollment PBB levels [30]. Assuming the decay model holds for levels below $2 \mathrm{ppb}$, and assuming BMI constant, the current PBB estimates would not be biased. If the decay model fails below $2 \mathrm{ppb}$, third-order kinetics may apply. If the true half-life is shorter for enrollment PBBs below $2 \mathrm{ppb}$ than above, then the decay model would overestimate current PBB levels, given a woman's BMI. In this case, women with low PBB levels at interview would be misclassified in higher adjusted PBB tertiles, and differences in cycle length or bleed length may be underestimated. If the true half-life is longer for enrollment PBBs below 2 $\mathrm{ppb}$, then we would observe an overestimation of effect. We extrapolated our results further out to the time of the MFHS interview (22.4 years maximum) than the original decay model (11.1 years maximum). We acknowledge that this longer extrapolation is a limitation; however, data on long-term decay are not available. We believe that by using this decay model to estimate current PBB exposure that either no bias or an underestimation of effect is more likely, given the complex and nonlinear relationship between initial PBB level, BMI, and half-life described by Blanck et al [30].

Laboratory detection methods for PBBs changed over time to include $\mathrm{PCB}$ and pesticide determinations, and are described elsewhere [30,64], while early MDCH biologic sampling protocols did not require fasting blood draws nor standardization for serum lipids [2,60,64-68]. Nonfasting samples have higher mean concentrations of lipophilic compounds and higher total serum lipids than fasting samples. Postprandial increases in serum lipids have been shown to fluctuate with serum chlorinated hydrocarbon levels over a 24-hour period [69]. The lack of fasting requirements may add some measurement error in this present study; however; we believe that it would result in nondifferential misclassification. A woman's exposure status, even if known, is unlikely to prompt her decision to eat in relation to the time of a blood draw. Therefore, bias would most likely be toward the null hypothesis.

More recently, Schisterman et al proposed that lipid standardization is highly prone to bias, and advocate careful definitions of a causal framework for exposure, lipids, and health outcomes. There are study design frameworks when models not standardized for total lipids, equivalent to wet weight analyses, would be preferred [70]. Estrogens and other exogenous hormones are believed to alter plasma lipid and lipoprotein levels [71], and we hypothesize that potential endocrine disruptors, like PBBs or PCBs, may do the same. Since adiposity, energy homeostasis, and ovulation are believed to be intrinsically related [72], adjusting PBB or PCB levels for serum lipids could inappropriately adjust for the exposures themselves [70]. If this framework for the interrelationships holds true, then our lack of lipid standardization may not necessarily be a limitation. Statistical differences have been previously noted comparing lipid adjusted and wet weight analyses. When Cooper et al adjusted their menstrual cycle analyses for lipids, their serum-lipid analyses between PCBs with cycle length were somewhat attenuated compared to wet-weight analyses, but not with bleed length [10].

Our PBB exposure levels quantify only of the main congener, PBB 153. Different PBB congeners may have different endocrine-related effects related to menstrual function as suggested in some studies of PCBs $[10,11]$ and by other proposed disruptors [62,73-78]. In congener-specific analyses, Cooper et al observed shorter cycle length with increasing exposure to PCB 52. This is in contrast to cycle lengthening when total PCBs are considered [10]. Windham et al noted that cycle length may decrease with increasing levels of PCB 187 but not with other congeners [11]. Rat and hamster models for follicular atresia and ovulatory delay with phenobarbital administration have been demonstrated [75-78], and PBB 153 is a phenobarbital-type inducer [27]. Among smokers, folliculotoxic effects of polycyclic aromatic hydrocarbons on primordial oocytes have been implicated in earlier menopause [7982], while no relation between $\mathrm{PBB}$ exposure and time to menopause was found among women in the MFHS [83]. Other chemicals believed to alter endocrine function include dichlorodiphenyltrichloroethane (DDT), 1,1dichloro-2,2-bis( $p$-chlorophenyl)ethylene (DDE), and polybrominated diphenyl ethers (PBDEs) $[10,11,84,85]$. The MFHS is limited by the lack of extensive information on these additional exposures.

\section{Conclusion}

This study suggests that PBB exposure may impact ovarian function as indicated by menstrual cycle length and bleed length. However, these associations were found among the small number of women with recent weight loss suggesting either a chance finding or that mobilization of PBBs from lipid stores may be important. These results should be replicated with larger numbers of women exposed to lipophilic compounds. 


\section{List of Abbreviations}

BMI body mass index

CDF cumulative distribution function

DDE 1,1-dichloro-2,2-bis( $p$-chlorophenyl)ethylene

DDT dichlorodiphenyltrichloroethane

LOD limit of detection

MDCH Michigan Department of Community Health

MFHS Michigan Female Health Study

PBB polybrominated biphenyl

PBDE polybrominated diphenyl ether

PCB polychlorinated biphenyl

Ppb parts per billion

QQ quantile-quantile

\section{Competing interests}

The author(s) declare that they have no competing interests.

\section{Authors' contributions}

SID conceived, carried out, and interpreted the analytical models and drafted the manuscript. MM was Principal Investigator and PET, CO-PI of the MFHS funded by the U.S. Environmental Protection Agency and the National Institute of Environmental Health Sciences. In that capacity they were responsible for scientific decisions regarding the study. LLC is PI of the Michigan PBB Long-Term Study at the MDCH. VSH oversaw the statistical analyses. MM, PET, HMB, CR and $\mathrm{AKH}$, developed and implemented the protocol for the MFHS, assisted by LLC. HMB, MM, PET, $\mathrm{AKH}$, and VSH conceived and developed the exponential decay mathematical model for the MFHS. LLC and the MDCH study staff provided the investigators access to the cohort, laboratory, and interview data archives on study participants and provided cohort outreach. All authors read and approved the final manuscript.

\section{Acknowledgements}

Research was funded by the U.S. Environmental Protection Agency (R 825300-0 I-I), the National Institute of Environmental Health Sciences and the National Institutes of Health Office of Women's Health (ROI ES0834I$\mathrm{OI})$, and the Centers for Disease Control and Prevention cooperative agreement (U37/CCU500392).

The assistance of Peter McGuire and the staff of the Michigan PBB LongTerm Study, MDCH, and the generosity of cohort members are gratefully acknowledged. Dana Flanders provided valuable advice on statistical analyses and interpretation.

\section{References}

I. Meester WD: The effect of polybrominated biphenyls on man: the Michigan PBB disaster. Vet Hum Toxicol 1979, 2I(Suppl): |3|-| 35 .

2. Landrigan PJ, Wilcox KR, Silva J, Humphrey HEB, Kauffman C, Heath $\mathrm{C}$ : Cohort study of Michigan residents exposed to polybrominated biphenyls: epidemiologic and immunologic findings. Ann NY Acad Sci 1979, 320:284-294.

3. Lambrecht LK, Barsotti DA, Allen JR: Responses of nonhuman primates to a polybrominated biphenyl mixture. Environ Health Perspect 1978, 23:139-145.

4. Allen JR, Carstens LA, Barsotti DA: Residual effects of shortterm, low-level exposure of nonhuman primates to polychlorinated biphenyls. Toxicol Appl Pharmacol 1974, 30:440-45I.

5. Allen JR, Barsotti DA, Carstens LA: Residual effects of polychlorinated biphenyls on adult nonhuman primates and their offspring. J Toxicol Environ Health 1980, 6:55-66.

6. Arnold DL, Bryce F, Stapley R, McGuire PF, Burns D, Tanner JR, Karpinski K: Toxicological consequences of Aroclor 1254 ingestion by female rhesus (Macaca mulatta) monkeys. Part IA. Prebreeding phase: clinical health findings. Food Chem Toxicol 1993, 31:799-8I0.

7. Truelove JF, Tanner JR, Langlois A, Stapley RA, Arnold DL, Mes JC: Effect of polychlorinated biphenyls on several endocrine reproductive parameters in the female rhesus monkey. Arch Environ Contam Toxicol 1990, 19:939-943.

8. Bryce F, Hayward S, Stapley R, Arnold DL: Consequences of Aroclor 1254 ingestion on the menstrual cycle of rhesus (Macaca mulatta) monkeys. Food Chem Toxicol 2000, 38:1053-1064.

9. Mendola P, Buck GM, Sever LE, Maria Zielezny, Vena JE: Consumption of PCB-contaminated freshwater fish and shortened menstrual cycle length. Am J Epidemiol 1997, I 46:955-960.

10. Cooper GS, Klebanoff MA, Promislow J, Brock JW, Longnecker MP: Polychlorinated biphenyls and menstrual cycle characteristics. Epidemiology 2005, I 6(2):19|-200.

II. Windham GC, Lee D, Mitchell P, Anderson M, Petreas M, Lasley B: Exposure to organochlorine compounds and effects on ovarian function. Epidemiology 2005, 16(2): I82-190.

12. Yu ML, Guo YL, Hsu CC, Rogan WJ: Menstruation and reproduction in women with polychlorinated biphenyl (PCB) poisoning: long-term follow-up interviews of the women from the Taiwan Yucheng cohort. Int J Epidemiol 2000, 29:672-677.

13. Marchetti B, Morale MC, Guarcello V, Cutuli N, Raiti F, Batticane N, Palumbo G, Farinella Z, Scapagnini U: Cross-talk communication in the neuroendocrine-reproductive-immune axis. Agedependent alterations in the common communication networks. Ann NY Acad Sci 1990, 594:309-325.

14. Mosley RL: Aging, immunity and neuroendocrine hormones. Adv Neuroimmunol 1996, 6:419-432.

15. Genazzani AR, Petraglia F, Gamba O, Sgarbi L, Greco M, Genazzi AD: Neuroendocrinology of the menstrual cycle. Ann NY Acad Sci 1997, 816:143-150.

16. Brenner PF: Differential diagnosis of abnormal uterine bleeding. Am J Obstet Gynecol 1996, I 75(3):766-769.

17. Sillem M, Rabe T, Runnebaum B: Effect of central and ovarian endocrine disturbances on the female genital tract - clinical signs and symptoms. Verh Dtsch Ges Pathol 1997, 81:191-196.

18. Wathen PI, Henderson MC, Witz CA: Abnormal uterine bleeding. Med Clin North Am 1995, 79:329-344.

19. Munro MG: Dysfunctional uterine bleeding: advances in diagnosis and treatment. Curr Opin Obstet Gynecol 200I, 13:475-489.

20. Reynolds LP, Grazul-Bilska AT, Redmer DA: Angiogenesis in the female reproductive organs: pathological implications. Int J Exp Pathol 2002, 83:15I-164.

21. Kleinbaum DG, Kupper LL, Morgenstern H: Epidemiologic Research: Principles and Quantitative Methods. New York, New York: Van Nostrand Reinhold; 1982.

22. Fries GF: The PBB episode in Michigan: an overall appraisal. CRC Crit Rev Toxicol 1985, 16:105-156.

23. Metcalf MG: Incidence of ovulation from the menarche to the menopause: observations of $622 \mathrm{New}$ Zealand women. NZ Med J 1983, 96:645-648. 
24. Harlow SD, Zeger SL: An application of longitudinal methods to the analysis of menstrual diary data. J Clin Epidemiol I991, 44:1015-1025

25. Harlow SD, Lin X, Ho MJ: Analysis of menstrual diary data across the reproductive life span applicability of the bipartite model approach and the importance of within-woman variance. J Clin Epidemiol 2000, 53:722-733.

26. Creinin MD, Keverline S, Meyn LA: How regular is regular? An analysis of menstrual cycle regularity. Contraception 2004, 70:289-292

27. Dent JG: Characteristics of cytochrome P-450 and mixed function oxidase enzymes following treatment with PBBs. Environ Health Perspect 1978, 23:30I-307.

28. Needham LL, Burse VW, Price HA: Temperature-programmed gas chromatographic determination of polychlorinated and polybrominated biphenyls in serum. J Assoc Off Anal Chem 1981, 64: $1131-1137$.

29. Burse VW, Needham LL, Liddle JA, Bayse DD, Price HA: Interlaboratory comparison for results of analyses for polybrominated biphenyls in human serum. I Anal Toxicol 1980, 4:22-26.

30. Blanck HM, Marcus M, Hertzberg V, Tolbert PE, Rubin C, Henderson AK, Zhang RH: Determinants of polybrominated biphenyl serum decay among women in the Michigan PBB cohort. Environ Health Perspect 2000, 108: I47-152.

31. Blanck HM, Marcus M, Tolbert PE, Rubin C, Henderson AK, Hertzberg VS, Zhang RH, Cameron L: Age at menarche and tanner stage in girls exposed in utero and postnatally to polybrominated biphenyl. Epidemiology 2000, I I:64I-647.

32. Schantz SL, Jacobson JL, Humphrey HB, Jacobson SW, Welch R, Gasior D: Determinants of polychlorinated biphenyls in the sera of mothers and children from Michigan farms with PCBcontaminated silos. Arch Environ Health 1994, 49:452-458.

33. Hornung RW, Reed LW: Estimation of the average concentrations in the presence of non-detectable values. Appl Occup Environ Hyg 1990, 5:46-5I.

34. Bahn AK, Mills JL, Snyder PJ, Gann PH, Houten L, Bialik O, Hollmann L, Utiger RD: Hypothyroidism in workers exposed to polybrominated biphenyls. N Engl J Med I 980, 302:3 I-33.

35. Hood A, Hashmi R, Klaassen CD: Effects of microsomal enzyme inducers of thyroid-follicular cell proliferation, hyperplasia, and hypertrophy. Toxicol Appl Pharmacol 1999, 160:163-170.

36. Hood A, Klaassen CD: Differential effects of microsomal enzyme inducers on in vitro thyroxine $\left(T_{4}\right)$ and triiodothyronine $\left(\mathbf{T}_{3}\right)$ glucuronidation. Toxicol Sci 2000, 55:78-84.

37. Barter RA, Klaassen CD: Reduction of thyroid hormone levels and alteration of thyroid function by four representative UDP-glucuronosyltransferase inducers in rats. Toxicol Appl Pharmacol 1994, 128:9-17.

38. Byrne JJ, Carone JP, Hanson EA: Hypothyroidism and abnormalities in the kinetics of thyroid hormone metabolism in rats treated chronically with polychlorinated biphenyl and polybrominated biphenyl. Endocrinology 1987, I 2 1:520-527.

39. Zhu YS, Yen PM, Chin WW, Pfaff DW: Estrogen and thyroid hormone interaction on regulation of gene expression. Proc Nat Acad Sci 1996, 93: I 2587-12592.

40. Wakim AN, Paljug WR, Jasnosz KM, Alkahim N, Brown AB, Burholt DR: Thyroid hormone receptor messenger ribonucleic acid in human granulosa and ovarian stromal cells. Fertil Steril 1994 62:531-534.

41. Doufas AG, Mastorakos G: The hypothalamic-pituitary-thyroid axis and the female reproductive system. Ann NY Acad Sci 2000, 900:65-76.

42. Loucks AB, Mortola JF, Girton L, Yen SSC: Alterations in the hypothalamic-pituitary-ovarian and the hypothalamic-pituitary-adrenal axes in athletic women. J Clin Endocrinol Metab 1989, 68:402-4II

43. Hu RM, Han ZG, Song HD, Peng YD, Huang $Q H$, Ren SX, Gu YJ, Huang CH, Li YB, Jiang CL, Fu G, Zhang QH, Gu BW, Dai M, Mao YF, Gao GF, Rong R, Ye M, Zhou J, Xu SH, Gu J, Shi JX, Jin WR, Zhang CK, Wu TM, Huang GY, Chen Z, Chen MD, Chen JL: Gene expression profiling in the human hypothalamus-pituitary-adrenal axis and full-length cDNA cloning. Proc Natl Acad Sci 2000 , 97:9543-9548.

44. Kondoh Y, Uemura T, Murase M, Yokoi N, Ishikawa M, Hirahara F: A longitudinal study of disturbances of the hypothalamic-pitui- tary-adrenal axis in women with progestin-negative functional hypothalamic amenorrhea. Fertil Steril 200I, 76:748-752.

45. Cooper G, Sandler DP, Whelan EA, Smith KR: Association of physical and behavioral characteristics with menstrual cycle patterns in women aged 29-3 I years. Epidemiology 1996, 7:624-628.

46. Harlow SD, Campbell BC: Host factors that influence the duration of menstrual bleeding. Epidemiology 1994, 5:352-355.

47. Sternfeld B, Jacobs MK, Quesenberry CP, Gold EB, Sowers M: Physical activity and menstrual cycle characteristics in two prospective cohorts. Am J Epidemiol 2002, 156:402-409.

48. Falsetti L, Pasinetti E, Mazzani MD, Gastaldi A: Weight loss and menstrual cycle: clinical and endocrinological evaluation. Gynecol Endocrinol 1992, 6:49-56.

49. Schweiger $U$, Laessle R, Pfister $H$, Hoehl $C$, Schwingenschloegel $M$, Schweiger M, Pirke KM: Diet-induced menstrual irregularities: effects of age and weight loss. Fertil Steril 1987, 48:746-75 I.

50. Schweiger U, Tuschl RJ, Platte P, Broocks A, Laessle RG, Pirke KM: Everyday eating behavior and menstrual function in young women. Fertil Steril 1992, 57:77I-775.

5I. Pirke KM, Schweiger U, Strowitzki T, Tuschl RJ, Laessle RG, Broocks A, Huber B, Middendorf R: Dieting causes menstrual irregularities in normal weight young women through impairment of episodic luteinizing hormone secretion. Fertil Steril 1989, 51:263-268.

52. De Souza MJ, Miller BE, Loucks AB, Luciano AA, Pescatello LS, Campbell CG, Lashley BL: High incidence of luteal phase deficiency and anovulation in recreational female runners: blunted elevation in follicle-stimulating hormone observed during luteal-follicular transition. J Clin Endocrinol Metab 1998, 83:4220-4232.

53. Klein NA, Battaglia DE, Fujimoto VY, Davis GS, Bremner WJ, Soules MR: Reproductive aging: accelerated ovarian follicular development associated with a monotropic follicle-stimulating hormone rise in normal older women. J Clin Endocrinol Metab 1996, 81:1038-1045

54. Richardson SJ, Senikas V, Nelson JF: Follicular depletion during the menopausal transition: evidence for accelerated loss and ultimate exhaustion. J Clin Endocrinol Metab 1987, 65:I23I-I 237.

55. Faddy MJ, Gosden RG: A mathematical model of follicle dynamics in the human ovary. Hum Reprod 1995, 10:770-775.

56. Faddy MJ, Gosden RG: A model conforming the decline in follicle numbers to the age of menopause in women. Hum Reprod | 996, I I: | 484-| 486.

57. Chevrier J, Dewailly E, Ayotte P, Mauriege P, Despres JP, Tremblay A: Body weight loss increases plasma and adipose tissue concentrations of potentially toxic pollutants in obese individuals. Int J Obes Relat Metab Disord 2000, 24: I 272-I278.

58. Walford RL, Mock D, MacCallum T, Laseter JL: Physiologic changes in humans subjected to severe, selective calorie restriction for two years in Biosphere 2: health, aging, and toxicological perspectives. Toxicol Sci 1999, 52(Suppl):6I-65.

59. Longnecker MP, Klebanoff MA, Gladen BC, Berendes HW: Serial levels of serum organochlorines during pregnancy and postpartum. Arch Environ Health 1999, 54: I I0-I I4.

60. Eyster JT, Humphrey HEB, Kimbrough RD: Partitioning of polybrominated biphenyls (PBBS) in serum, adipose tissue, breast milk, placenta, cord blood, biliary fluid, and feces. Arch Environ Health 1983, 38:47-53.

6I. Stoker TE, Goldman JM, Cooper RL: Delayed ovulation and pregnancy outcome: effect of environmental toxicants on the neuroendocrine control of the ovary. Environ Toxicol Pharmacol 2001, 9:117-129.

62. Eskenazi B, Warner M, Mocarelli P, Samuels S, Needham LL, Patterson DG, Lippman S, Vercellini P, Gerthoux PM, Brambilla P, Olive D: Serum dioxin concentrations and menstrual cycle characteristics. Am J Epidemiol 2002, 156:383-392.

63. Taffe J, Dennerstein L: Retrospective self-report compared with menstrual diary data prospectively kept during the menopausal transition. Climacteric 2000, 3:|83-19|.

64. Kreiss K, Roberts C, Humphrey HE: Serial PBB levels, PCB levels, and clinical chemistries in Michigan's PBB cohort. Arch Environ Health 1982, 37:|41-147.

65. Wolff MS, Haymes N, Anderson HA, Selikoff IJ: Family clustering of PBB and DDE values among Michigan dairy farmers. Environ Health Perspect 1978, 23:3।5-3|9. 
66. Wolff MS, Aubrey B: PBB homologs in sera of Michigan dairy farmers and Michigan chemical workers. Environ Health Perspect 1978, 23:211-215.

67. Wolff MS, Aubrey B, Camper F, Haymes N: Relation of DDE and PBB serum levels in farm residents, consumers, and Michigan Chemical Corporation employees. Environ Health Perspect 1978, 23:|77-|8|.

68. Wolff MS, Anderson HA, Rosenman KD, Selikoff IJ: Equilibrium of polybrominated biphenyl (PBB) residues in serum and fat of Michigan residents. Bull Environ Contam Toxicol 1979, 21:775-78I.

69. Phillips DL, Pirkle JL, Burse VW, Bernert JT Jr, Henderson LO, Needham LL: Chlorinated hydrocarbon levels in human serum: effects of fasting and feeding. Arch Environ Contam Toxicol 1989, 18:495-500.

70. Schisterman EF, Whitcomb BW, Louis GM, Louis TA: Lipid Adjustment in the Analysis of Environmental Contaminants and Human Health Risks. Environ Health Perspect 2005, I I 3:853-857.

7I. Barnett JB, Woods MN, Lamon-Fava S, Schaefer EJ, McNamara JR, Spiegelman D, Hertzmark E, Goldin B, Longcope C, Gorbach SL: Plasma lipid and lipoprotein levels during the follicular and luteal phases of the menstrual cycle. J Clin Endocrinol Metab 2004, 89:776-782.

72. Steel JH, White R, Parker MG: Role of the RIP I 40 corepressor in ovulation and adipose biology. J Endocrinol 2005, 185: I-9.

73. Matikainen T, Perez GI, Juriscova A, Pru JK, Schlezinger JJ, Ryu HY, Laine J, Sakai T, Korsmeyer SJ, Casper RF, Sherr DH, Tilly JL: Aromatic hydrocarbon receptor-driven Bax gene expression is required for premature ovarian failure caused by biohazardous environmental chemicals. Nature Genetics 200I, 28:355-360.

74. Gao X, Son DS, Terranova PF, Rozman KK: Toxic equivalency factors of polychlorinated dibenzo-p-dioxins in an ovulation model: validation of the toxic equivalency concept for one aspect of endocrine disruption. Toxicol Appl Pharmacol 1999, 157:107-116.

75. Braw RH, Tsafriri A: Follicles explanted from pentobarbitonetreated rats provide a model for atresia. J Reprod Fertil 1980, 59:259-265.

76. Terranova PF: Effects of phenobarbital-induced ovulatory delay on the follicular population and serum levels of steroids and gonadotropins in the hamster: a model for atresia. Biol Reprod 1980, 23:92-99.

77. Na JY, Garza F, Terranova PF: Alterations in follicular fluid steroids and follicular hCG and FSH binding during atresia in hamster. Proc Soc Exp Biol Med 1985, 179:123-127.

78. Terranova PF, Uilenbroek JT, Saville L, Horst D, Nakamura Y: Serotonin enhances oestradiol production by hamster preovulatory follicles in vitro: effects of experimentally induced atresia. J Endocrinol 1990, I 25:433-438.

79. Westhoff C, Murphy P, Heller D: Predictors of ovarian follicle number. Fertil Steril 2000, 74:624-628.

80. Midgette AS, Baron JA: Cigarette smoking and the risk of natural menopause. Epidemiology 1990, I:474-480.

81. Harlow BL, Signorello LB: Factors associated with early menopause. Maturitas 2000, 35:3-9.

82. Kato I, Toniolo P, Akhmedkhanov A, Koenig KL, Shore R, ZeleniuchJacquotte A: Prospective study of factors influencing the onset of natural menopause. J Clin Epidemiol 1998, 5I:127I-I276.

83. Blanck HM, Marcus M, Tolbert PE, Schuch C, Rubin C, Henderson AK, Zhang RH, Hertzberg VS: Age at menopause in relation to PBBs, PCBs, and smoking. Maturitas 2004, 49:97-106.

84. Schecter A, Papke O, Tung KC, Joseph J, Harris TR, Dahlgren J: Polybrominated diphenyl ether flame retardants in the U.S. population: current levels, temporal trends, and comparison with dioxins, dibenzofurans, and polychlorinated biphenyls. Occup Environ Med 2005, 47(3): 199-2II.

85. Petreas M, She J, Brown FR, Winkler J, Windham G, Rogers E, Zhao G, Bhatia R, Charles MI: High body burdens of 2,2',4,4'-tetrabromodiphenyl ether (BDE-47) in California women. Environ Health Perspect 2003, I I I (9): I I75-I I 79.
Publish with Biomed Central and every scientist can read your work free of charge

"BioMed Central will be the most significant development for disseminating the results of biomedical research in our lifetime. "

Sir Paul Nurse, Cancer Research UK

Your research papers will be:

- available free of charge to the entire biomedical community

- peer reviewed and published immediately upon acceptance

- cited in PubMed and archived on PubMed Central

- yours - you keep the copyright

Submit your manuscript here:

http://www.biomedcentral.com/info/publishing_adv.asp
BiolMedcentral 